\title{
DNMT3A Mutations in Patients with Acute Myeloid Leukemia in South Brazil
}

\author{
Annelise Pezzi, ${ }^{1,2}$ Lauro Moraes, ${ }^{1}$ Vanessa Valim,, 2 Bruna Amorin,, ${ }^{1,2}$ Gabriela Melchiades, ${ }^{1}$ \\ Fernanda Oliveira, ${ }^{1}$ Maria Aparecida da Silva, ${ }^{1,2}$ Ursula Matte, ${ }^{3}$ \\ Maria S. Pombo-de-Oliveira, ${ }^{4}$ Rosane Bittencourt, ${ }^{5}$ Liane Daudt, ${ }^{5}$ and Lúcia Silla ${ }^{1,2,5,6}$ \\ ${ }^{1}$ Cellular Therapy Center, Center for Experimental Research, Hospital de Clinicas de Porto Alegre, \\ 90035-903 Porto Alegre, RS, Brazil \\ ${ }^{2}$ Postgraduate Course of Medical Sciences, Federal University of Rio Grande do Sul, 90035-903 Porto Alegre, RS, Brazil \\ ${ }^{3}$ Gene Therapy Center, Center for Experimental Research, Hospital de Clinicas de Porto Alegre, 90035-903 Porto Alegre, RS, Brazil \\ ${ }^{4}$ Pediatric Hematology and Oncology Program, Research Center, Instituto Nacional de Câncer, 20230-130 Rio de Janeiro, RJ, Brazil \\ ${ }^{5}$ Hematology and Bone Marrow Transplantation, Hospital de Clinicas de Porto Alegre, 90035-903 Porto Alegre, RS, Brazil \\ ${ }^{6}$ Laboratory of Cell Culture and Molecular Analysis of Hematopoietic Cells, Center for Experimental Research, \\ Hospital de Clínicas de Porto Alegre, 2350 Ramiro Barcelos, 90035-903 Porto Alegre, RS, Brazil
}

Correspondence should be addressed to Lúcia Silla, 1silla@hcpa.ufrgs.br

Received 18 July 2012; Revised 1 October 2012; Accepted 1 October 2012

Academic Editor: Helen A. Papadaki

Copyright (C) 2012 Annelise Pezzi et al. This is an open access article distributed under the Creative Commons Attribution License, which permits unrestricted use, distribution, and reproduction in any medium, provided the original work is properly cited.

Acute myeloid leukemia (AML) is a complex and heterogeneous hematopoietic tissue neoplasm. Several molecular markers have been described that help to classify AML patients into risk groups. DNA methyltransferase 3A (DNMT3A) gene mutations have been recently identified in about $22 \%$ of AML patients and associated with poor prognosis as an independent risk factor. Our aims were to determine the frequency of somatic mutations in the gene DNMT3A and major chromosomal translocations in a sample of patients with AML. We investigated in 82 samples of bone marrow from patients with AML for somatic mutations in DNMT3A gene by sequencing and sought major fusion transcripts by RT-PCR. We found mutations in the DNMT3A gene in 6 patients $(8 \%) ; 3$ were type R882H. We found fusion transcripts in 19 patients, namely, AML1/ETO $(n=5 ; 6.1 \%), \operatorname{PML} / \mathrm{RAR} \alpha(n=12$; $14.6 \%)$, MLL/AF9 $(0 ; 0 \%)$, and CBF $\beta / \mathrm{MYH} 11(n=2 ; 2.4 \%)$. The identification of recurrent mutations in the DNMT3A gene and their possible prognostic implications can be a valuable tool for making treatment decisions. This is the first study on the presence of somatic mutations of the DNMT3A gene in patients with AML in Brazil. The frequency of these mutations suggests a possible ethnogeographic variation.

\section{Introduction}

Acute myeloid leukemia (AML) is a complex and heterogeneous hematopoietic tissue neoplasm caused by gene mutations, chromosomal rearrangements, deregulation of gene expression, and epigenetic modifications. These changes lead to unregulated proliferation and loss of differentiation capacity of myeloid hematopoietic cells. In recent years, several important prognostic molecular markers have been described for AML which not only improved disease characterization, but also allowed stratification of patients into risk groups and can guide therapeutic decision-making [1]. However, these molecular markers are often unable to provide accurate prognostic and therapeutic information, since the course of the disease varies significantly between patients belonging to the same risk category [2-4].

The traditional view of cancer as a disease caused by some genetic mutation has been replaced by the concept of a complex network of gene deregulation and epigenetic changes. Additionally, although extremely important, those mutations that have been reported are found in only a minority of patients with AML [5-7]. The distinct components of epigenetic machinery such as DNA methylation, covalent modifications of histones, and noncoding RNAs have been described as cocontrollers of gene expression and within 
a context of cancer may contribute to leukemogenesis [8]. Methyltransferases such as DNMT1, DNMT3A, and DNMT3B are key components of the epigenetic regulation of genes as they catalyze the addition of methyl groups to the cytosine residue of $\mathrm{CpG}$ dinucleotides.

Recently, in a study using whole genome sequencing, recurrent somatic mutations have been described in the DNA methyltransferase $3 \mathrm{~A}$ gene (DNMT3A) in $22 \%$ of patients with AML [9]. In this study, DNMT3A mutations were independently associated with a poor prognosis and more frequent in patients with normal cytogenetics and as such, of utmost clinical relevance. Eighteen different mutations were found, most of them missense mutations. Preliminary data show that the incidence of these mutations in AML ranges from $4.1 \%$ in a Japanese study [10], $9 \%$ in a study with Chinese patients [11], and about $15-25 \%$ in two Western studies [9, 12-14]. Given the association with CN-AML observed in all studies, it is not astonishing that the highest prevalence was reported in the 2 series focusing on $\mathrm{CN}$ AML (29-36\%) [15, 16]. These possible ethnogeographic differences in the incidence of DNMT3A mutations as well as their prognostic role need, however, to be better characterized. The exact mechanisms by which of DNMT3A mutations act in AML are still unclear, since the global pattern of methylation in the genome of such patients with AML does not appear to be significantly changed [9].

The aim of this study was to characterize the frequency and clinical impact of mutations in the DNMT3A gene, correlating it with clinical data and with already well defined translocations in AML in a group of patients treated at the Hospital das Clinicas, in Porto Alegre, Rio Grande do Sul, Brazil.

\section{Materials and Methods}

2.1. Patients. We have studied 87 samples of bone marrow from patients with AML, at diagnosis and prior to any chemotherapy, which had been cryopreserved at the Laboratory of Cell Culture and Molecular Analysis of Hematopoietic Cells belonging to the Center for Experimental Research at the Hospital de Clinicas of Porto Alegre (CPE-HCPA) since 2001 to the present date. The patients' clinical information was obtained from the AML database of the Service of Hematology and Bone Marrow Transplantation of HCPA. Patients were stratified into risk groups-favorable, intermediate, and high-according to the WHO criteria [17]. The favorable subgroup is represented by recurrent reciprocal translocations $\mathrm{t}(15 ; 17), \mathrm{t}(8 ; 21)$, and inv(16); the intermediate includes patients with a normal karyotype, +8 and $\mathrm{t}(9 ; 11)$; and the unfavorable subgroup includes complex karyotypes ( $\geq 3$ abnormality) -5 and -7 abnormalities, anomalies of chromosome 3 , and balanced structural rearrangements as: $t(6 ; 9), t(6 ; 11)$, and $t(11 ; 19)$. Karyotypic characterization of our sample is shown in Table 1.

The procedures were approved by the Ethical Committee of Human Experimentation in Brazil, and are in accordance with the Helsinki Declaration of 1975.
TABLE 1: Karyotypic characterization of our sample.

\begin{tabular}{lc}
\hline Result of karyotype result analysis & Number of pts $(\%)$ \\
\hline Normal & $38(61.3 \%)$ \\
$\mathrm{t}(15 ; 17)$ & $5(8.0 \%)$ \\
$\mathrm{t}(8 ; 21)$ & $4(6.4 \%)$ \\
Complex karyotype & $3(4.8 \%)$ \\
$\operatorname{del}(11)$ & $1(1.6 \%)$ \\
$\operatorname{del}(\mathrm{X})$ & $1(1.6) \%$ \\
$\operatorname{add}(7)$ & $1(1.6 \%)$ \\
$\mathrm{t}(6 ; 9)$ & $1(1.6 \%)$ \\
$\mathrm{t}(1 ; 2)$ & $1(1.6 \%)$ \\
$\mathrm{t}(18 ; 9)$ & $1(1.6 \%)$ \\
$\mathrm{t}(3 ; 21)$ & $1(1.6 \%)$ \\
$\mathrm{t}(10 ; 11)$ and del(7) & $1(1.6 \%)$ \\
add $(18)(21)(7)$ & $1(1.6 \%)$ \\
Trisomy 4 and 8 & $1(1.6 \%)$ \\
Tetraploid & $1(1.6 \%)$ \\
Polyploidy & $1(1.6 \%)$ \\
\hline
\end{tabular}

2.2. Extraction of DNA and RNA. Samples of cryopreserved bone marrow were thawed, washed with PBS1x with 5\% albumin, and then had their DNA and RNA extracted with Trizol Reagent (Invitrogen), according to the manufacturer's recommendations.

2.3. Identification of Fusion Transcripts. After RNA extraction we proceeded to reverse transcription using the SuperScript III kit (Invitrogen). The effectiveness of RNA extraction and of cDNA synthesis was monitored by the amplification of the constitutive gene glyceraldehyde-3-phosphate dehydrogenase $(G A P D H)$ and negative samples were discarded.

The sequences of interest were amplified by the polymerase chain reaction (PCR) according to BIOMED-1 [18] (Table 2). PCR products were visualized by electrophoresis on $1.5 \%$ agarose gel and bands were considered positive in the following sizes: $A M L-A / E T O-B: 395 \mathrm{bp}, P M L-A 1 / R A R \alpha-$ B: 381 bp, PML-A2/RAR $\alpha-B$ : 376 bp, CBF $\beta-A / M Y H 11-B 2$ : 418, and MLL6S/AF9AS3: 651 bp [18, 19].

2.4. Identification of Mutations in DNMT3A Gene. The extracted DNA was amplified by PCR at the DNMT3A exons $19,20,21,22$, and 23, with primers described by Thol et al. [14] (Table 2). After electrophoresis on 1.5 agarose gel, PCR products were subjected to purification using Exonuclease I and Shrimp Alkaline Phosphatase (EXO-SAP, GE Healthcare) and then sequenced.

2.5. Sequencing. Samples were sequenced at the Unidade de Análises Moleculares e de Proteínas (Centro de Pesquisa Experimental, HCPA) using ABI 3500 Genetic Analyzer with $50 \mathrm{~cm}$ capillaries and POP7 polymer (Applied Biosystems). PCR products were labeled with $3.2 \mathrm{pmol}$ of the forward primer and $1 \mu \mathrm{L}$ of BigDye Terminator v3.1 Cycle Sequencing Kit (Applied Biosystems) in a final volume of $10 \mu \mathrm{L}$. Labeled samples were purified using BigDye XTerminator 
TABLE 2: Primer sequences for genes of interest.

\begin{tabular}{|c|c|c|}
\hline Chromosomal translocation & Fusion transcript & Sequence $\left(5^{\prime}-3^{\prime}\right)$ \\
\hline \multirow{2}{*}{$\mathrm{t}(8 ; 21)$} & AML1-A & CTACCGCAGCCATGAAGAACC \\
\hline & ETO-B & AGAGGAAGGCCCATTGCTGAA \\
\hline \multirow{3}{*}{$\mathrm{t}(15 ; 17)$} & PML-A1 & CAGTGTACGCCTTCTCCATCA \\
\hline & PML-A2 & CTGCTGGAGGCTGTGGAC \\
\hline & $\mathrm{RAR} \alpha-\mathrm{B}$ & GCTTGTAGATGCGGGGTAGA \\
\hline \multirow{2}{*}{ inv16 } & $\mathrm{CBF} \beta-\mathrm{A}$ & GCAGGCAAGGTATATTTGAAGG \\
\hline & MYH11-B2 & TCСТСТTСТССТСATTCTGCTC \\
\hline \multirow{2}{*}{$\mathrm{t}(9 ; 11)$} & MLL6S & GCAAACAGAAAAAAGTGGCTCCCCG \\
\hline & AF9AS3 & TCACGATCTGCTGCAGAATGTGTCT \\
\hline Gene & Exon & Sequence $\left(5^{\prime}-3^{\prime}\right)$ \\
\hline \multirow{2}{*}{ DNMT3A } & \multirow{2}{*}{ Exon 19} & CACCACTGTCCTATGCAGACA \\
\hline & & ATTAGTGAGCTGGCCAAACC \\
\hline \multirow{2}{*}{ DNMT3A } & \multirow{2}{*}{ Exon 20} & CCTTGGCTCATCTTCAAACC \\
\hline & & CACTATGGGTCATCCCACCT \\
\hline \multirow{2}{*}{ DNMT3A } & \multirow{2}{*}{ Exon 21} & CCGCTGTTATCCAGGTTTCT \\
\hline & & CCCAGCAGAGGTTCTAGACG \\
\hline \multirow{2}{*}{ DNMT3A } & \multirow{2}{*}{ Exon 22} & TTTGGTAGACGCATGACCAG \\
\hline & & AGCACAGCAATCAGAACAGC \\
\hline \multirow{2}{*}{ DNMT3A } & \multirow{2}{*}{ Exon 23} & TCCTGCTGTGTGGTTAGACG \\
\hline & & ATGATGTCCAACCCTTTTCG \\
\hline
\end{tabular}

Purification Kit (Applied Biosystems) and electroinjected in the automatic sequencer. Electropherograms were compared to the reference sequence (NM_022552). Altered sequencing results were confirmed by reverse strand sequencing.

2.6. Statistical Analysis. Statistical analysis was performed using SPSS V18. Overall Survival and Disease-Free Survival curves were calculated using the Kaplan-Meier survival function and comparison by the Long Rank test. For categorical data Fisher's exact test was used. $P$ value of less than 0.05 was considered statistically significant.

\section{Results}

3.1. Characterization of the Sample. Of the 87 AML samples taken from the cell bank of the Laboratory of Cell Culture and Molecular Analysis of Hematopoietic Cell, 82 could be analyzed. Of the studied patient population, 58.5\% (48) were male with a median age of 42 years. According to the FAB classification, 6.8\% (5) were AML M0, 21.9\% (16) AML M1, 30.1\% (22) AML M2, 19.2\% (14) AML M3, 17.8\% (13) AML M4, 1.4\% (1) AML M5, and 2.7\% (2) were classified as AML and not M3. The median white blood cell (WBC) count at diagnosis was $6.6 \times 10^{9} / \mathrm{L}$ ranging from 0.16 to $374.5 \times 10^{9} / \mathrm{L}$. There were $23(41.8 \%)$ cases with karyotype alterations. As for risk stratification, 18 (29\%) patients were allocated to the favorable group, $38(61.3 \%)$ to the intermediate group, $6(9.7 \%)$ belonged to the unfavorable risk group, and in $20(16.4 \%)$ karyotypic analysis was not performed and therefore could not be classified (Table 3 ).
As shown in Table 3, we were able to stratify into risk categories only 62 patients since for 20 of them we did not have enough information. Eighteen $(29.0 \%)$ were in the favorable, $38(61.3 \%)$ in the intermediate, and $6(9.7 \%)$ in the unfavorable risk group. Except for the group of patients with AML M3 who were treated according to the APL protocol [20], all other patients received remission induction and consolidation using the protocol $7+3$, and intensification with high doses of AraC. Of these, 8 were subsequently submitted to autologous and 22 to allogeneic bone marrow transplantation (BMT). Of the entire group, $14(19.2 \%)$ were refractory to treatment. Of these, $1(7.1 \%)$ belonged to the favorable, $8(57.1 \%)$ to the intermediate, $2(14.2 \%)$ to the unfavorable, and $3(21.4 \%)$ belonged to the unclassified group. The overall survival (OS) of the 62 categorized patients, with a followup of 120 months, was $54.9 \%, 39.0 \%$, and $16.7 \%$ for favorable, intermediate, and unfavorable risk category, respectively $(P=0.15)$ (Figure 1). The OS and disease-free survival (DFS) of the entire group of patients, with a followup of 120 months, was $41.7 \%$ and $23.4 \%$, respectively (Figure 2 ).

3.2. Fusion Transcripts. Nineteen patients (23.1\%) had fusion transcripts identified by RT-PCR. Five (6.1\%) presented the AML1/ETO, 12 (14.6\%) PML/RAR $\alpha$, and $2(2.4 \%)$ the $C B F \beta / M Y H 11$ fusion genes. The presence of $M L L / A F 9$ $\mathrm{t}(9 ; 11)$ was not found in our series of AML patients. The transcript $P M L / R A R \alpha$ was identified in $78.5 \%$ (11) of the cases classified as APL. Of the $12 P M L / R A R \alpha$ positive patients, only 4 had a compatible karyotype, positive for 
TABLE 3: Characteristics of the entire patient population.

\begin{tabular}{|c|c|}
\hline Variable & Number of patients (\%) \\
\hline \multicolumn{2}{|l|}{ Age $-n=82$} \\
\hline Median (SD) & $42(18.5)$ \\
\hline Mean (SD) & $40.6(18.5)$ \\
\hline Range & $3-75$ \\
\hline \multicolumn{2}{|l|}{ Sex $-n=82$} \\
\hline Male & $58.5 \%(48)$ \\
\hline Female & $41.5 \%(34)$ \\
\hline \multicolumn{2}{|c|}{ FAB classification- $n=73$} \\
\hline M0 & $6.8 \%(5)$ \\
\hline M1 & $21.9 \%(16)$ \\
\hline M2 & $30.1 \%(22)$ \\
\hline M3 & $19.2 \%(14)$ \\
\hline M4 & $17.8 \%(13)$ \\
\hline M5 & $1.4 \%(1)$ \\
\hline M6 & $0 \%(0)$ \\
\hline M7 & $0 \%(0)$ \\
\hline AML not M3 & $2.4 \%(2)$ \\
\hline \multicolumn{2}{|l|}{ Karyotype $-n=55$} \\
\hline Normal & $58.2 \%(32)$ \\
\hline With alteration & $41.8 \%(23)$ \\
\hline \multicolumn{2}{|c|}{ Risk classification- $n=62$} \\
\hline Favorable & $29 \%(18)$ \\
\hline Intermediate & $61.3 \%(38)$ \\
\hline Unfavorable & $9.7 \%(6)$ \\
\hline \multicolumn{2}{|c|}{ Leukocytes $\left(\times 10^{9} / \mathrm{L}\right)-n=82$} \\
\hline Median (SD) & $6.6(51.9)$ \\
\hline
\end{tabular}

$t(15 ; 17)$, and the remaining had either normal (3) or no karyotype (5).

When comparing the overall survival for positive and negative PML/RAR $\alpha$ patients, with a followup of 120 months, we observed that the OS was $72.7 \%$ for positive and $37.6 \%$ for the negative $(P=0.19)$ (Figure 1). A tendency for prognostic value was also shown for the presence of AML1/ETO with an OS of $22.7 \%$ and $60.2 \%$ for positive and negative, respectively $(P=0.19)$. Finally, one of the inv16 patients died during remission induction and the other is still alive in continuous complete remission.

3.3. DNMT3A. Somatic mutations were found in $8 \%$ (6) of the samples, being 5 missensemutations and one silent mutation, including the p.R882H mutation described by Ley et al. [9] that was identified in 3 patients. All variant sequences were heterozygous and no patient had more than one mutation. The new mutations found were: p.R973Q, p.D748N, and p.H896. The mutations location domains are shown in Figure 3. Of the 6 cases with DNMT3A mutations, the majority (5, or $83.3 \%$ ) were located in exon 23 . Four $(80.0 \%)$ patients with mutations belonged to the intermediate risk group with normal karyotype, 1 to the favorable group, and 1 unclassified. Of the patients with DNMT3A mutation, only 1 was positive for the fusion transcript
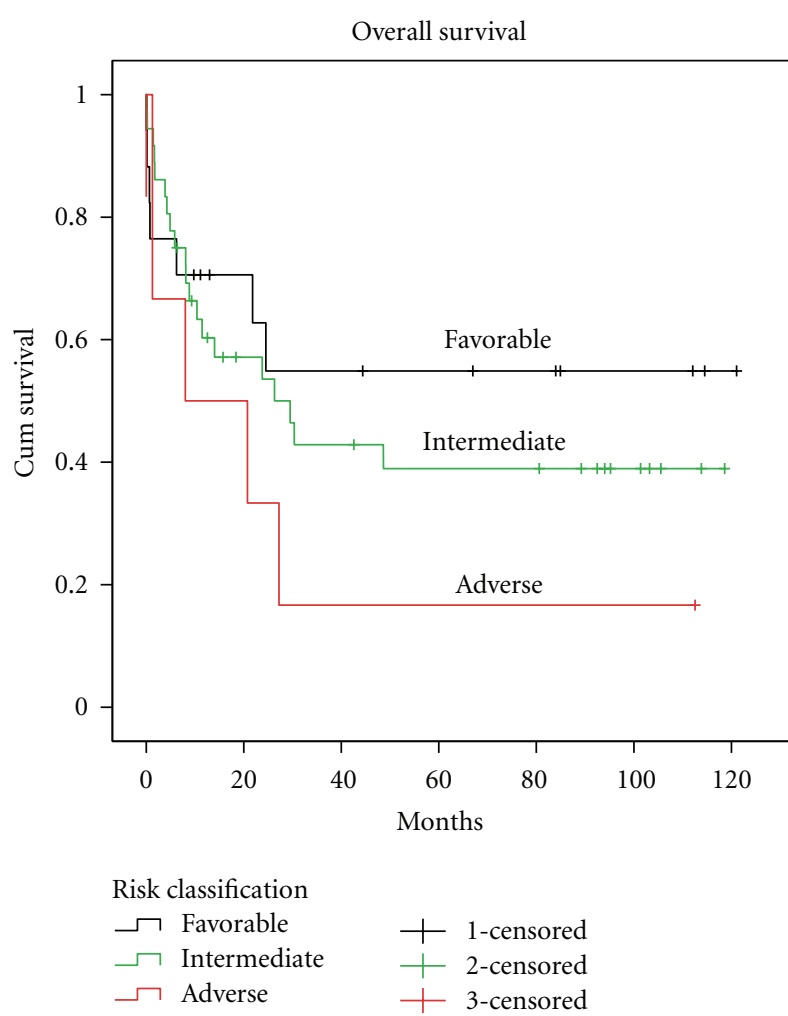

FIGURE 1: Comparison of the estimated overall survival according to the risk category with a followup of 120 months: favorable (54.9\%), intermediate $(39 \%)$, and unfavorable $(16.7 \%)(P=0.15)$.

$P M L / R A R \alpha$ and died of coagulopathy during induction; the patient with trisomy 4 and 8 is alive in continuous remission (Table 4).

The characteristics of patients with or without DNMT3A gene mutation did not differ significantly, and they are represented in Table 5. Although the sample size does not allow a comparative analysis of survival, with a followup of 120 months, OS for patients with wild DNMT3A gene was $41.4 \%$ and for patients with mutated DNMT3A was $44.4 \%(P=$ $0.59)$; the SLD was $22.7 \%$ and $0 \%$, respectively $(P=0.32)$.

\section{Discussion}

Of the 82 patients studied, we were able to classify 73 according to the FAB classification. The frequency of FAB subtypes M0, M1, and M2 was similar to that reported in the literature except for subtypes M4, M5, M6, and M7 whose frequency was lower (Table 3 ). The M3 subtype was more frequent (19.2\%) in our group when compared with international studies; this confirms the results reported by Capra et al. [21] in a study in Rio Grande do Sul, Brazil and is similar to that reported by others for the Latin American population $[22,23]$. The frequency distribution of FAB classification subtypes we found in our sample was the same described in 532 AML cases we reported [21] in the same region with patients with the same ethnic background. Based on this finding we can say that although now reporting a smaller sample of patients from a single institution, it 


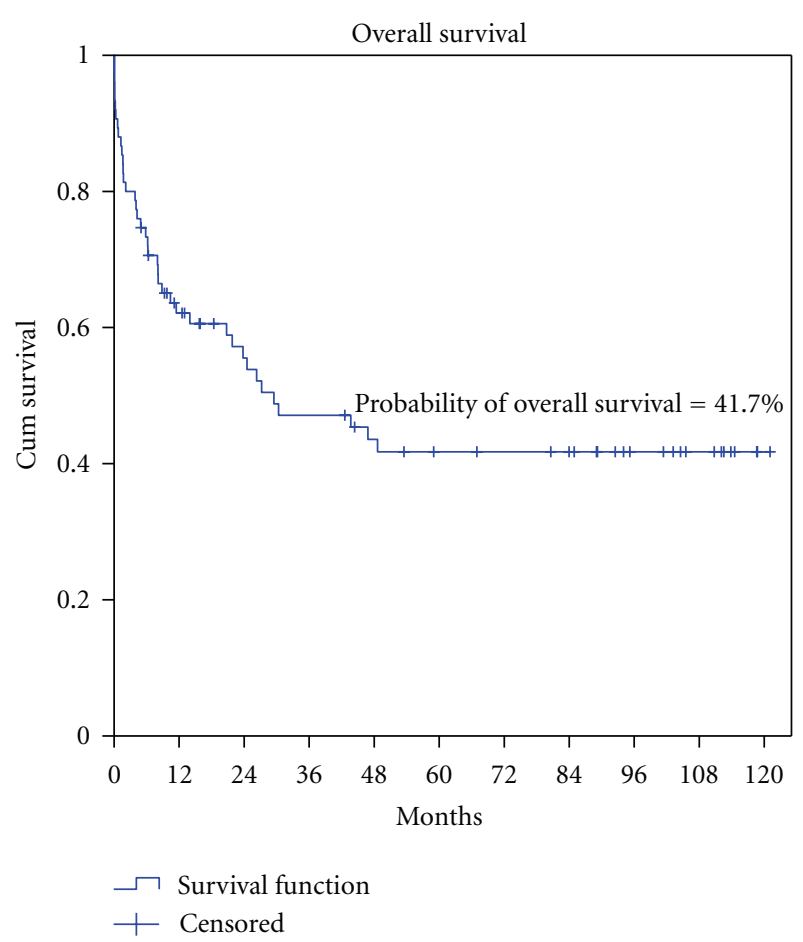

(a)

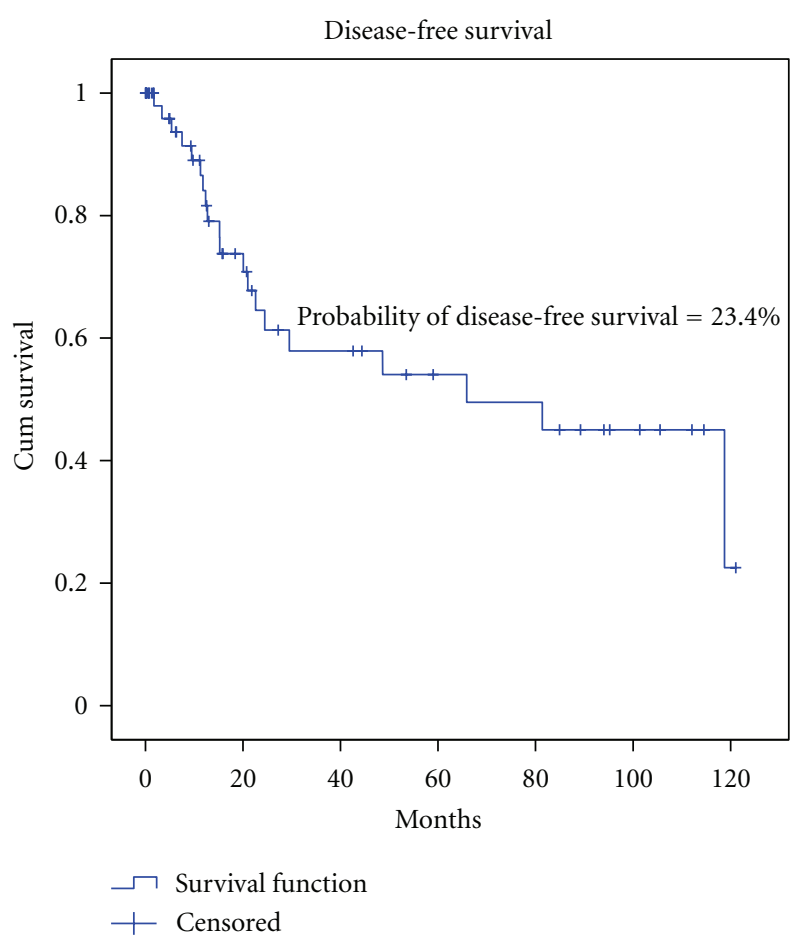

(b)

FIGURE 2: (a) Overall survival in a followup of 120 months with an estimated probability of overall survival of $41.7 \%$; (b) disease-free survival in a followup of 120 months with an estimated probability of disease-free survival of $23.4 \%$.

TABLE 4: Description of somatic mutations found in gene DNMT3A.

\begin{tabular}{lcccccccc}
\hline $\begin{array}{l}\text { Patient } \\
\text { identification }\end{array}$ & Mutation & Allelic change & Exon & $\begin{array}{c}\text { Type of } \\
\text { mutation }\end{array}$ & $\begin{array}{c}\text { FAB } \\
\text { subtype }\end{array}$ & PCR & Risk group & Karyotype \\
\hline 39 & D748N & G $>$ A & 19 & Missense & M1 & Negative & Intermediate & Normal \\
79 & R882H & G $>$ A & 23 & Missense & M1 & Negative & Intermediate & Trisomy (8)(9) \\
4 & R882H & G $>$ A & 23 & Missense & M3 & Negative & Intermediate & Normal \\
70 & R882H & G $>$ A & 23 & Missense & M2 & Negative & Intermediate & Normal \\
41 & H896 & A $>$ G & 23 & Silent & M3 & PML/RAR $\alpha$ & Favorable & t(15;17) \\
78 & R973Q & G $>$ A & 23 & Missense & - & Negative & - & - \\
\hline
\end{tabular}

is a representative of our population. Our institution is a university public hospital with one of the most active bone marrow transplantation centers in the country to where AML patients from all over the state are referred for treatment. Regarding the classification of risk found in our sample of $29.0 \%, 61.3 \%$, and $9.7 \%$ for the favorable, intermediate, and unfavorable risk categories, respectively, in spite of having a significant number of cases not classified, in general it agrees with the distribution described in the literature and is virtually identical to that reported in patients in the same region of the country [21].

The frequency of fusion transcripts, particularly the AML1/ETO found in $6.1 \%$ of our sample, was similar to that described in the literature (6 a 12\%) [24, 25], while the relative frequency of $P M L / R A R \alpha(14.6 \%)$ was higher (5-8\%) [26], probably reflecting the higher incidence of AML M3 in our population. For the transcript $C B F \beta / M Y H 11$ we had a relative frequency of $2.4 \%$, slightly lower than the $(5-8 \%)$ reported by others [27], and none positive for the transcript $M L L / A F 9$, which correlates with the literature, which indicates a frequency of approximately $1 \%$ [19]. However, in general, the finding of rearrangements in $22 \%$ of our patients is consistent with the frequency of 20\% found in 1065 patients in the UK [28]. Finally, the analysis of chromosomal translocations by RT-PCR proved to be advantageous in our center since only 7 of the 19 patients with fusion transcripts were detected by karyotype analysis, explaining the frequency of only $41.8 \%$ of karyotype abnormalities found in our group of patients, less than the 65\% reported by Look [29].

The search for recurrent somatic mutations in the gene DNA methyltransferase 3A (DNMT3A) was performed in all our 82 patients. We chose to sequence the last five exons of the gene DNMT3A since, as demonstrated by Ley et al. [9], 
TABLE 5: Clinical characteristics of patients with acute myeloid leukemia with or without DNMT3A mutations.

\begin{tabular}{lcc}
\hline Characteristics & Number of pts (\%) DNMT3A mutated & Number of pts (\%) DNMT3A not mutated \\
\hline Age (median) & 40.2 & 44.8 \\
Sex & & $P$ \\
Male & $50 \%(3)$ & $59.3 \%(45)$ \\
Female & $50 \%(3)$ & $40.7 \%(31)$ \\
Subtype FAB & & \\
M0 & $0 \%$ & $7.2 \%(5)$ \\
M1 & $60 \%(3)$ & $18.8 \%(13)$ \\
M2 & $20 \%(1)$ & $30.4 \%(21)$ \\
M3 & $20 \%(1)$ & $20.3 \%(14)$ \\
M4 & $0 \%$ & $18.8 \%(13)$ \\
M5 & $0 \%$ & $1.4 \%(1)$ \\
Not M3 & $0 \%$ & $2.9 \%(2)$ \\
Risk groups & & \\
Favorable & $20 \%(1)$ & $29.8 \%(17)$ \\
Intermediate & $80 \%(4)$ & $59.6 \%(34)$ \\
Unfavorable & $0 \%$ & $10.5 \%(6)$ \\
Leukocytes $\left(\times 10^{3}\right)($ median $)$ & 20.67 & 6.41 \\
Death & $50 \%(3)$ & $51.4 \%(37)$ \\
Relapses & $50 \%(2)$ & $30.9 \%(17)$ \\
Refractory & $20 \%(1)$ & $19.1 \%(13)$
\end{tabular}

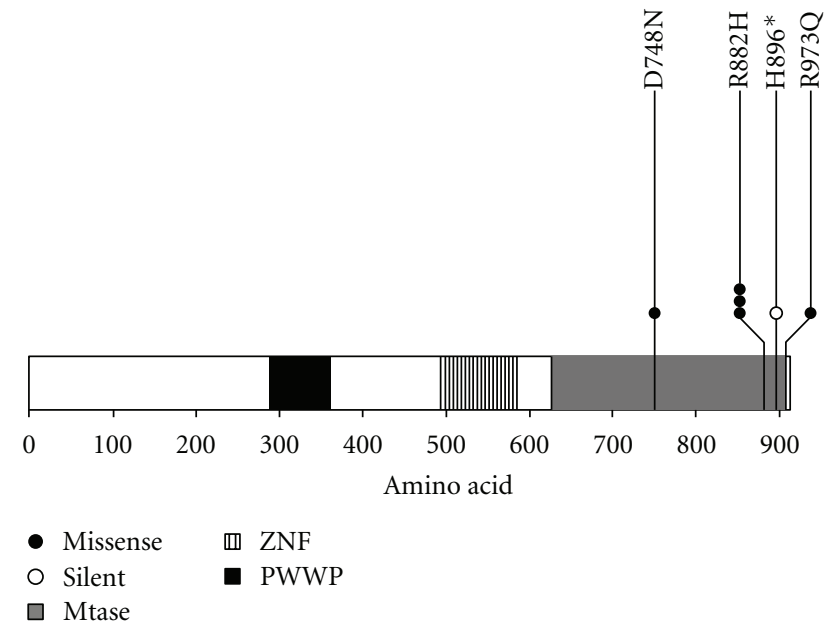

FIGURE 3: Location and classification of gene mutations found in gene DNMT3A. Representation of the DNMT3A gene and its domains: methyltransferase (MTase), zinc-finger (ZNF), and conserved proline-tryptophan-tryptophan-proline (PWWP).

approximately $80 \%$ of the mutations were located in these exons, with $58 \%$ of them in the last one (exon 23 ), where, in fact, most mutations in our study were found (Figure 3 ). The frequency of somatic DNMT3A mutations found in $8 \%$ of our 82 cases is lower than the $22 \%$ reported in 281 patients by Ley et al. [9], and lower than the $17.8 \%$ found by Thol et al. [14], also in Western patients, including about 500 patients. Interestingly, although the first study has sequenced the entire gene, in the latter only the last nine exons were studied. The lowest frequency of mutations in our sample appears similar to that reported for patients of other ethnic groups. In a Japanese study [10], including 74 patients and sequencing the entire gene, the frequency of mutations was found to be only $4.1 \%$, all located in exon 23 , while in a Chinese study [11] including 355 patients and also sequencing the entire gene, the frequency of mutations, predominately affecting exon 23 , was approximately $9 \%$.

As for the sequences of DNMT3A gene variants, in accordance with a study of Stegelmann et al. [30], all our cases were heterozygous and no patient had more than one mutation; in addition, 3 of 6 mutations were p.R882H, already described by Ley et al. [9] who found a frequency of $59 \%$ of such mutation.

Five, or $80 \%$, of our patients harboring a DNMT3A mutation belonged to the intermediate risk category, as was reported by others [9]. We also found a tendency $(P=0.28)$ to an increased leukocyte number at diagnosis for patients with mutation $\left(20.7 \times 10^{9} / \mathrm{L}\right)$ comparing to the ones without mutation $\left(6.4 \times 10^{9} / \mathrm{L}\right)$ which is in agreement with those reported in numerous studies [9-11, 31-33]. Interestingly, and worth mentioning, in our group of patients there was one case of DNMT3A mutation that also harbored PML/ $R A R \alpha$.

Finally, the OS according to risk category in our group of 62 patients showed a prognostic trend similar to that reported in the literature (Figure 1). A prognostic evaluation for DNMT3A somatic mutations or its concurrency with fusion transcripts could not be determined in our study due to our sample size. 


\section{Conclusions}

In conclusion, to our knowledge, this is the first study on the presence of somatic mutations of the gene DNMT3A in patients with AML in Brazil. Although in a small number of patients, we found the frequency of these mutations to be lower than that reported for Western patients. This could indicate an ethnogeographical variation already suggested in the literature for Eastern and Caucasian patients [34]. The discovery of recurrent mutations in the gene DNMT3A and its possible prognostic implications can provide valuable information for risk stratification for patients with AML and represents a valuable tool for making therapeutic decisions. However, the use of mutations in the DNMT3A gene as a tool for risk stratification needs to be discussed considering their application in different ethnicgeographic groups.

\section{Acknowledgments}

The study received financial support from the Research and Event Incentive Fund of Hospital de Clínicas de Porto Alegre (FIPE-HCPA) and The National Council for Scientific and Technological Development (CNPq) and has been supported by $\mathrm{CNPq}$ research scholarship no. 309091/2007-10. This paper has no conflict of interests.

\section{References}

[1] S. Fröhling, C. Scholl, D. G. Gilliland, and R. L. Levine, "Genetics of myeloid malignancies: pathogenetic and clinical implications," Journal of Clinical Oncology, vol. 23, no. 26, pp. 6285-6295, 2005.

[2] R. D. Brunning and, "Classification of acute leukemias," Seminars in Diagnostic Pathology, vol. 20, pp. 142-153, 2003.

[3] T. Szczepanski, V. H. J. van Velden, and J. J. M. van Dongen, "Classification systems for acute and chronic leukemias," Best Practice \& Research Clinical Haematology, vol. 16, pp. 561-582, 2003.

[4] T. Peter and H. Andrew, "The epigenomics revolution in myelodysplasia: a clinic-pathological perspective," Hematopathology, vol. 43, pp. 536-546, 2011.

[5] C. Plass, C. Oakes, W. Blum, and G. Marcucci, "Epigenetics in acute myeloid leukemia," Seminars in Oncology, vol. 35, no. 4, pp. 378-387, 2008.

[6] O. Galm, S. Wilop, C. Lüders et al., "Clinical implications of aberrant DNA methylation patterns in acute myelogenous leukemia," Annals of Hematology, Supplement, vol. 84, no. 13, pp. 39-46, 2005.

[7] J. Boultwood and J. S. Wainscoat, "Gene silencing by DNA methylation in haematological malignancies," British Journal of Haematology, vol. 138, no. 1, pp. 3-11, 2007.

[8] P. A. Jones and S. B. Baylin, "The epigenomics of cancer," Cell, vol. 128, no. 4, pp. 683-692, 2007.

[9] T. J. Ley, L. Ding, M. J. Walter et al., "DNMT3A mutations in acute myeloid leukemia," The New England Journal of Medicine, vol. 363, no. 25, pp. 2424-2433, 2010.

[10] Y. Yamashita, J. Yuan, I. Suetake et al., "Array-based genomic resequencing of human leukemia," Oncogene, vol. 29, no. 25, pp. 3723-3731, 2010.

[11] X. J. Yan, J. Xu, Z. H. Gu et al., "Exome sequencing identifies somatic mutations of DNA methyltransferase gene DNMT3A in acute monocytic leukemia," Nature Genetics, vol. 43, no. 4, pp. 309-315, 2011.

[12] A. F. Ribeiro, M. Pratcorona, and C. Erpelinck-Verschueren, "Mutant DNMT3A: a marker of poor prognosis in acute myeloid leukemia," Blood, vol. 119, pp. 5824-5831, 2012.

[13] J. P. Patel, M. Gönen, and M. E. Figueroa, "Prognostic relevance of integrated genetic profiling in acute myeloid leukemia," The New England Journal of Medicine, vol. 366, no. 12, pp. 1079-1089, 2012.

[14] F. Thol, F. Damm, A. Lüdeking et al., "Incidence and prognostic influence of DNMT3A mutations in acute myeloid leukemia," Journal of Clinical Oncology, vol. 29, no. 21, pp. 28892896, 2011.

[15] G. Marcucci, K. H. Metzeler, S. Schwind et al., "Age related prognostic impact of different types of DNMT3A mutations in adults with primary cytogenetically normal acute myeloid leukemia," Journal of Clinical Oncology, vol. 30, no. 7, pp. 742$750,2012$.

[16] A. Renneville, N. Boissel, O. Nibourel et al., "Prognostic significance of DNA methyltransferase 3A mutations in cytogenetically normal acute myeloid leukemia: a study by the Acute Leukemia French Association," Leukemia, vol. 26, no. 6, pp. 1247-1254, 2011.

[17] S. H. Swerdlow, E. Campo, N. L. Harris et al., WHO Classification of Tumours of Hematopoietic and Lymphoid Tissues, International Agency for Research on Cancer (IARC), Lyon, France, 2008.

[18] J. J. M. Van Dongen, E. A. Macintyre, J. A. Gabert et al., "Standardized RT-PCR analysis of fusion gene transcripts from chromosome aberrations in acute leukemia for detection of minimal residual disease. Report of the BIOMED-1 Concerted Action: investigation of minimal residual disease in acute leukemia," Leukemia, vol. 13, no. 12, pp. 1901-1928, 1999.

[19] G. Mitterbauer, C. Zimmer, C. Fonatsch et al., "Monitoring of minimal residual leukemia in patients with MLL-AF9 positive acute myeloid leukemia by RT-PCR," Leukemia, vol. 13, no. 10, pp. 1519-1524, 1999.

[20] R. H. Jácomo, R. A. M. Melo, F. R. Souto et al., "Clinical features and outcomes of 134 Brazilians with acute promyelocytic leukemia who received ATRA and anthracyclines," Haematologica, vol. 92, no. 10, pp. 1431-1432, 2007.

[21] M. Capra, L. Vilella, W. V. Pereira et al., "Estimated number of cases, regional distribution and survival of patients diagnosed with acute myeloid leukemia between 1996 and 2000 in Rio Grande do Sul, Brazil," Leukemia and Lymphoma, vol. 48, no. 12, pp. 2381-2386, 2007.

[22] K. J. Phekoo, M. A. Richards, H. Møller, and S. A. Schey, “The incidence and outcome of myeloid malignancies in 2,112 adult patients in south East-England," Haematologica, vol. 91, no. 10, pp. 1400-1404, 2006.

[23] D. Douer, S. Preston-Martin, E. Chang, P. W. Nichols, K. J. Watkins, and A. M. Levine, "High frequency of acute promyelocytic leukemia among Latinos with acute myeloid leukemia," Blood, vol. 87, no. 1, pp. 308-313, 1996.

[24] C. Schoch, D. Haase, T. Haferlach et al., "Fifty-one patients with acute myeloid leukemia and translocation $\mathrm{t}(8 ; 21)$ ( $\mathrm{q} 22$ $\mathrm{q} 22)$ : an additional deletion in $9 \mathrm{q}$ is an adverse prognostic factor," Leukemia, vol. 10, no. 8, pp. 1288-1295, 1996.

[25] M. F. Chauffaille, D. Borri, and S. R. Martins, "Leucemia mielóide aguda $\mathrm{t}(8 ; 21)$ : freqüência em pacientes brasileiros," Revista Brasileira de Hematologia e Hemoterapia, vol. 26, no. 2, pp. 99-103, 2004.

[26] D. A. Arber, R. D. Brunning, M. M. Le Beau, S. H. Swerdlow, E. Campo, and N. L. Harris, "Acute myeloid leukaemia with 
recurrent genetic abnormalities," in WHO classification of tumours of haematopoietic and lymphoid tissues, pp. 110-23, IARC Press, Lyon, 4th edition, 2008.

[27] C. Schoch and T. Haferlach, "Cytogenetics in acute myeloid leukemia," Current Oncology Reports, vol. 4, no. 5, pp. 390397, 2002.

[28] D. Grimwade, H. Walker, G. Harrison et al., "The predictive value of hierarchical cytogenetic classification in older adults with acute myeloid leukemia (AML): analysis of 1065 patients entered into the United Kingdom Medical Research Council AML11 trial," Blood, vol. 98, no. 5, pp. 1312-1320, 2001.

[29] A. T. Look, "Oncogenic transcription factors in the human acute leukemias," Science, vol. 278, no. 5340, pp. 1059-1064, 1997.

[30] F. Stegelmann, L. Bullinger, R. F. Schlenk et al., "DNMT3A mutations in myeloproliferative neoplasms," Leukemia, vol. 25, no. 7, pp. 1217-1219, 2011.

[31] J. Marková, P. Michková, and K. Burèková, "Prognostic impact of DNMT3A mutations in patients with intermediate cytogenetic risk profile acute myeloid leukemia," European Journal of Haematology, vol. 88, no. 2, pp. 10-128, 2012.

[32] F. Thol, C. Winschel, A. Lüdeking et al., "Rare occurrence of DNMT3A mutations in myelodysplastic syndromes," Haematologica, vol. 96, no. 12, pp. 1870-1873, 2011.

[33] J. Lin, Y. Dm, J. Qian et al., "Recurrent DNMT3A R882 mutations in Chinese patients with acute myeloid leukemia and myelodysplastic syndrome," PLoS ONE, vol. 6, Article ID e26906, p. 10, 2011.

[34] C. Thiede, "Mutant DNMT3A: teaming up to transform," Blood, vol. 119, no. 24, Article ID 56157, 2012. 


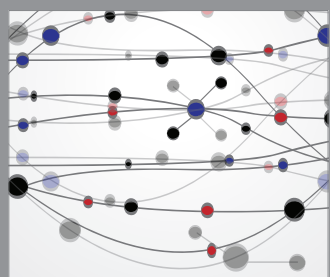

The Scientific World Journal
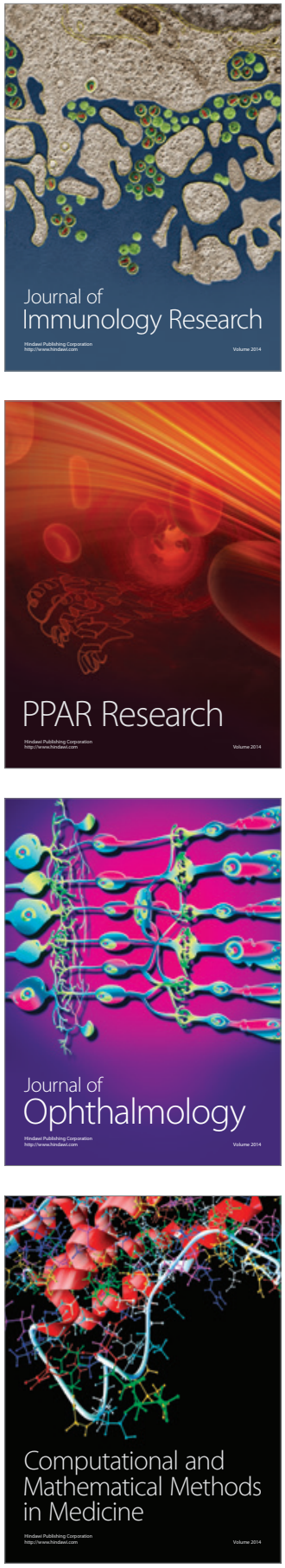

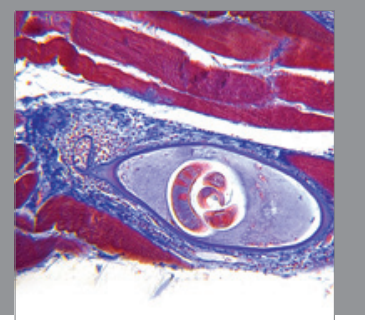

Gastroenterology

Research and Practice
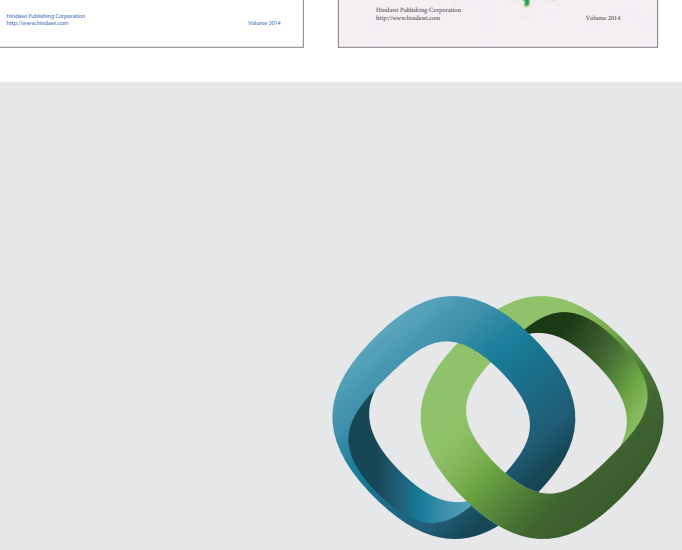

\section{Hindawi}

Submit your manuscripts at

http://www.hindawi.com
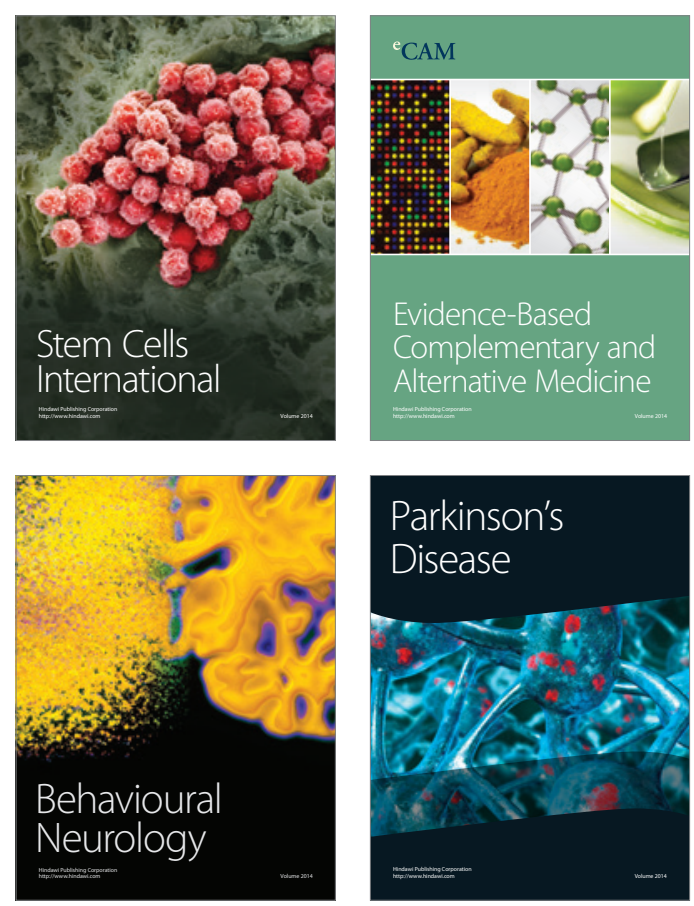

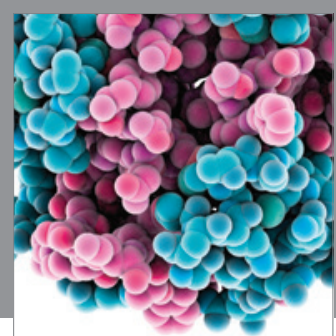

Journal of
Diabetes Research

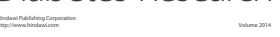

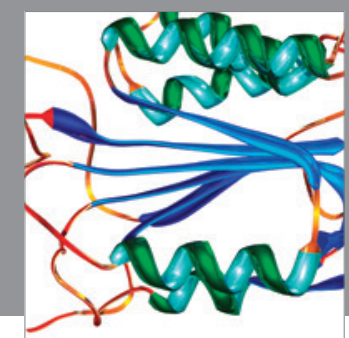

Disease Markers
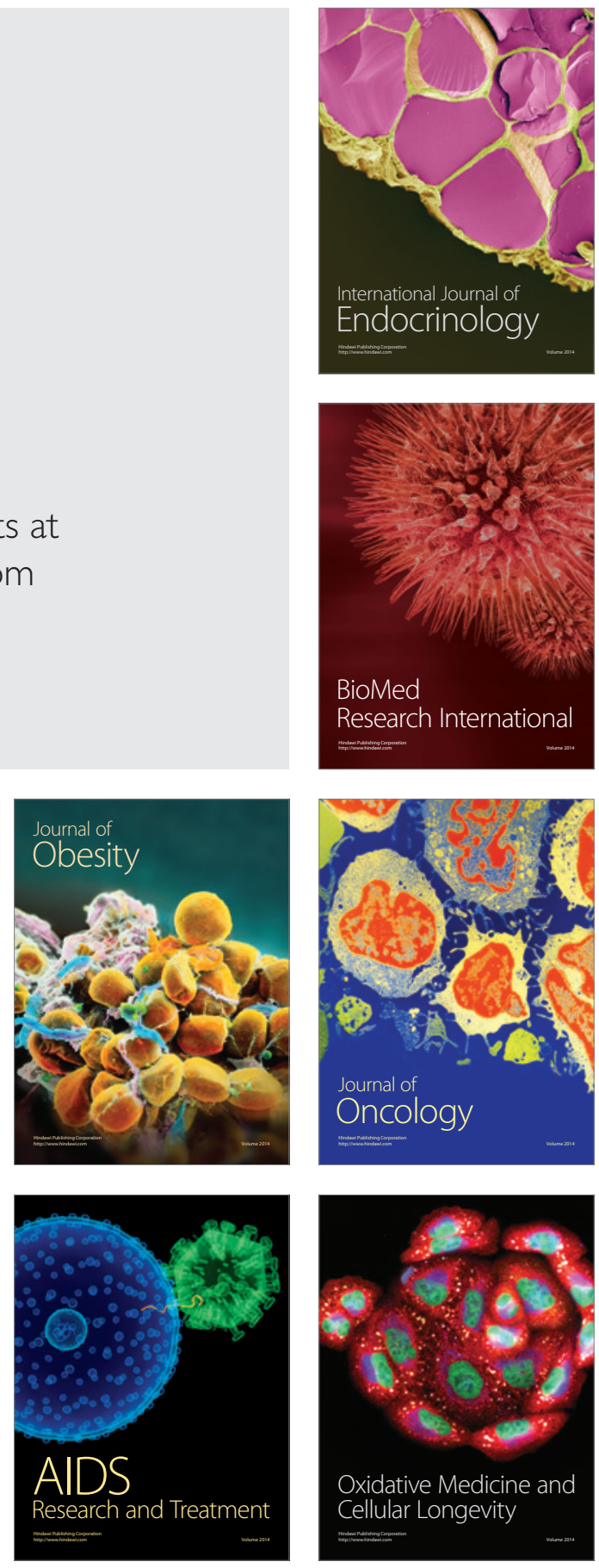